\title{
Safety of sildenafil in extremely premature infants: a phase I trial
}

Wesley Jackson (iD ${ }^{1 凶}$, Daniel Gonzalez ${ }^{2}$, P. Brian Smith $^{3,4}$, Namasivayam Ambalavanan (iD $^{5}$, Andrew M. Atz ${ }^{6}$, Gregory M. Sokol iD ${ }^{7}$, Chi D. Hornik $^{3,4}$, Dan Stewart iD $^{8}$, Gratias Mundakel ${ }^{9}$, Brenda B. Poindexter ${ }^{10}$, Shawn K. Ahlfeld ${ }^{11}$, Mary Mills ${ }^{4}$, Michael Cohen-Wolkowiez ${ }^{3,4}$, Karen Martz ${ }^{12}$, Christoph P. Hornik ${ }^{3,4}$, Matthew M. Laughon (iD) ${ }^{1}$ and Best Pharmaceuticals for Children Act-Pediatric Trials Network Steering Committee

(c) The Author(s), under exclusive licence to Springer Nature America, Inc. 2021

OBJECTIVE: To characterize the safety of sildenafil in premature infants.

STUDY DESIGN: A phase I, open-label trial of sildenafil in premature infants receiving sildenafil per usual clinical care (cohort 1) or receiving a single IV dose of sildenafil (cohort 2). Safety was evaluated based on adverse events (AEs), transaminase levels, and mean arterial pressure monitoring.

RESULTS: Twenty-four infants in cohort $1(n=25)$ received enteral sildenafil. In cohort 2, infants received a single IV sildenafil dose of $0.25 \mathrm{mg} / \mathrm{kg}(n=7)$ or $0.125 \mathrm{mg} / \mathrm{kg}(n=2)$. In cohort 2, there was one serious AE related to study drug involving hypotension associated with a faster infusion rate than specified by the protocol. There were no AEs related to elevated transaminases. CONCLUSION: Sildenafil was well tolerated by the study population. Drug administration times and flush rates require careful attention to prevent infusion-related hypotension associated with faster infusions of IV sildenafil in premature infants.

CLINICAL TRIAL: ClinicalTrials.gov Identifier: NCT01670136.

Journal of Perinatology (2022) 42:31-36; https://doi.org/10.1038/s41372-021-01261-w

\section{INTRODUCTION}

Bronchopulmonary dysplasia (BPD) is a common pulmonary morbidity in extremely premature infants. A common co-morbidity in premature infants with BPD is pulmonary hypertension $(\mathrm{PH})$. The prevalence of $\mathrm{PH}$ in infants with BPD ranges from 14 to $43 \%$ [1-5]. Infants with BPD-associated PH have higher mortality compared to infants with BPD who do not develop PH $[4,6$, 7]. Previous studies have identified various risk factors associated with $\mathrm{PH}$ in infants with BPD, including oligohydramnios [7], fetal growth restriction [2, 8], duration of respiratory support and oxygen therapy $[2,3,8]$, severity of $\operatorname{BPD}[3,8,9]$, and patent ductus arteriosus ligation $[2,3]$. There are currently few therapeutics available to prevent BPD and none are known to reduce mortality in infants with BPD-associated $\mathrm{PH}$.

Sildenafil is a potent inhibitor of type 5 phosphodiesterase, the predominant isoform in the lung that metabolizes cyclic guanosine monophosphate, resulting in pulmonary vasodilation. Although sildenafil is approved by the U.S. Food and Drug Administration (FDA) for treatment of PH in adults [10], studies in premature infants are limited [11]. Despite a paucity of pharmacokinetics (PK), safety, and efficacy data in this population, premature infants are increasingly receiving off-label sildenafil to treat PH [12].
We performed a phase I, multicenter, open-label trial designed to characterize PK and safety of sildenafil in two premature infant cohorts: the first cohort received sildenafil clinically at the discretion of the attending physician for treatment of $\mathrm{PH}$, and the second cohort received a single intravenous (IV) dose of sildenafil as per the study protocol. We used the data from the cohorts to develop a population PK model and design the next phase trial [13]. Here, we characterize the drug safety results from the phase I trial in premature infants receiving sildenafil.

\section{MATERIALS/SUBJECTS AND METHODS Patient population}

This study was a phase I, multicenter, open-label trial designed to characterize the PK and safety of sildenafil in premature infants to inform dosing for a phase II trial. The PK data were previously reported [13]. Infants in cohort 1 were $\leq 28$ weeks gestational age (GA), <365 postnatal days, and receiving sildenafil per usual clinical care. The only exclusion criterion for cohort 1 was any condition that would make the infant, in the opinion of the investigator, unsuitable for the study. Infants in cohort 2 were given a single dose of IV sildenafil with the following inclusion

\footnotetext{
${ }^{1}$ Department of Pediatrics, School of Medicine, The University of North Carolina at Chapel Hill, Chapel Hill, NC, USA. ${ }^{2}$ Division of Pharmacotherapy and Experimental Therapeutics, UNC Eshelman School of Pharmacy, The University of North Carolina at Chapel Hill, Chapel Hill, NC, USA. ${ }^{3}$ Department of Pediatrics, Duke University School of Medicine, Durham, NC, USA. ${ }^{4}$ Duke Clinical Research Institute, Durham, NC, USA. ${ }^{5}$ Division of Neonatology, School of Medicine, University of Alabama at Birmingham, Birmingham, AL, USA. ${ }^{6}$ Department of Pediatrics, Medical University of South Carolina Children's Hospital, Charleston, SC, USA. ${ }^{7}$ Division of Neonatal-Perinatal Medicine, Indiana University School of Medicine, Indianapolis, IN, USA. ${ }^{8}$ University of Louisville Norton Children's Hospital, Louisville, KY, USA. ${ }^{9}$ Kings County Hospital Center/SUNY Downstate Medical Center, Brooklyn, NY, USA. ${ }^{10}$ Department of Pediatrics, Emory University and Children's Healthcare of Atlanta, Atlanta, GA, USA. ${ }^{11}$ Department of Pediatrics, University of Cincinnati College of Medicine, Cincinnati Children's Hospital Medical Center, Cincinnati, OH, USA. ${ }^{12}$ The Emmes Company, LLC, Rockville, MD, USA. ${ }^{\circledR e m a i l: ~ w e s l e y . j a c k s o n @ u n c . e d u ~}$
} 
criteria: <32 weeks GA; 3-42 postnatal days; receiving mechanical ventilation, nasal continuous positive airway pressure, high-flow $(\geq 1.5 \mathrm{~L} / \mathrm{min})$ nasal cannula, or fraction of inspired oxygen $\left(\mathrm{FiO}_{2}\right)>$ $21 \%$ (and therefore at high risk of developing BPD); and IV access. We excluded infants with previous exposure to sildenafil within 7 days prior to enrollment; on a vasopressor for hypotension; known sickle cell disease; history of allergic reactions to sildenafil; or aspartate aminotransferase (AST) $>225 \mathrm{U} / \mathrm{L}$ or alanine aminotransferase $(A L T)>150 \mathrm{U} / \mathrm{L}$.

Six centers enrolled infants in cohort 1 and 5 of these centers enrolled at least 1 infant in cohort 2 . Local institutional review boards approved the protocol, and written informed consent was obtained from the parent(s)/legal guardian(s) of infants in both cohorts. We performed the study under an Investigational New Drug (IND) application (IND\#: 112374) with the FDA. Based on FDA guidance, we used a single IV dose study design in cohort 2 to establish a margin of safety before proceeding to multiple doseescalating courses in a planned phase II trial. We collected clinical and PK data as part of the Pediatric Trials Network study titled Pharmacokinetics of Sildenafil in Premature Infants.

\section{Drug dosing and lab collections}

In cohort 1, infants received enteral (compounded suspension) or IV administration of sildenafil per clinical care. An interim PK analysis was conducted after the first 12 participants were enrolled in cohort 1 to determine the appropriate dose for use in cohort 2: the single IV dose sildenafil group. The six doses prior to obtaining consent were recorded as clinical care doses, and all doses given for 7 days after enrollment were recorded as study doses. We did not record how long participants were receiving sildenafil prior to enrollment. In cohort 2, infants received a single IV dose of sildenafil $0.25 \mathrm{mg} / \mathrm{kg}$ administered over $90 \mathrm{~min}$ followed by a 30 -min flush, which was subsequently changed to an IV dose of $0.125 \mathrm{mg} / \mathrm{kg}$ over $90 \mathrm{~min}$ followed by a $60-\mathrm{min}$ flush due to an episode of hypotension. For cohort 1, the compounding, dispensing, and distribution of sildenafil was done by the local clinical or investigational pharmacy per sites' local policy. For cohort 2, we administered a commercially available IV formulation of sildenafil (Revatio ${ }^{\circ}$ ). In cohort 1, baseline AST and ALT were obtained within 7 days prior to the start of first study dose and within 7 days following first study dose. Hematology and serum chemistry labs were obtained per routine medical care and recorded for 7 days after first study dose. In cohort 2, baseline AST and ALT were obtained within $72 \mathrm{~h}$ prior to study drug administration, and follow-up AST and ALT at $24 \mathrm{~h}( \pm 16 \mathrm{~h})$ after study drug administration. Hematology and serum chemistry labs were obtained per routine medical care and recorded for $72 \mathrm{~h}$ prior to and $72 \mathrm{~h}$ after study dose of sildenafil.

\section{Safety Monitoring}

Adverse events (AEs) were collected during and after sildenafil administration and tabulated by MedDRA system organ class and preferred term. All AEs, including serious adverse events (SAEs), suspected adverse reactions (SARs), and adverse reactions (ARs), were recorded for 7 days following first study dose of sildenafil in cohort 1 and $72 \mathrm{~h}$ following the dose in cohort 2 . In cohort 2, all mean arterial pressure (MAP) values were obtained within $24 \mathrm{~h}$ of the start of sildenafil infusion, at baseline (start of sildenafil infusion) and at the following time points: $30 \mathrm{~min}$ after infusion start, $1 \mathrm{~h}$ after infusion start, infusion end, and 2, 4, 12, and $24 \mathrm{~h}$ after infusion start. We also recorded minimum MAP value during $24 \mathrm{~h}$ after infusion start. Additional vital signs (e.g., temperature, heart rate, and respiratory rate) were also recorded at the same time intervals. Low blood pressure was defined as one MAP $<G A$ at birth in weeks, and hypotension was defined as 2 MAP values < $\mathrm{GA}$, from the start of the sildenafil infusion through $24 \mathrm{~h}$ after the start of the infusion. The definitions were changed in the 0.125 $\mathrm{mg} / \mathrm{kg}$ dosing group to one MAP<postmenstrual age (PMA), defined as GA at birth in weeks plus postnatal age in weeks, for low blood pressure, and 2 MAP values < PMA for hypotension. A Data Monitoring Committee (DMC) performed a planned interim safety analysis after the first 12 participants were enrolled in cohort 1. Enrollment continued during the safety evaluation.

\section{Analysis}

The targeted sample size of 24 infants in cohort 1 and 16 infants in cohort 2 was based on the ability to observe a serious toxicity rate and to characterize the PK of sildenafil. Descriptive statistics, such as number of observations, mean, median, standard deviation, standard error, minimum, and maximum for continuous variables and counts, proportions, and percentages for discrete variables, were used to present infant demographic and baseline characteristics by cohort. Variables include race, age, sex, and selected clinical variables recorded prior to initiation of drug.

Serum AST and ALT laboratory measurements and changes from baseline are described using univariable descriptive statistics. Cohort 1 includes lab values obtained at baseline, any day while receiving sildenafil, and any follow-up day. Cohort 2 includes lab values at baseline, day of sildenafil administration, and any follow-up day. Lab tests reflective of liver toxicity (i.e., AST, ALT) are summarized in terms of the most extreme values and largest changes from baseline observed from the start of sildenafil through end of drug administration. The data analysis was performed by The Emmes Company, LLC. The authors assume full responsibility for the completeness and accuracy of the content of the manuscript.

\section{RESULTS}

\section{Demographics and dosing data}

A total of 34 infants were enrolled in the study; 25 infants in cohort 1 , and 9 infants in cohort 2 . We did not achieve target enrollment in cohort 2 because the pace of enrollment was deemed too slow to continue. Demographic and clinical data from infants in each cohort are presented in Table 1. All 34 infants received a study dose and completed the study as planned. Infants born to Black mothers comprised $72 \%$ of cohort 1 and $33 \%$ of infants in cohort 2. The median gestational age in both cohorts was 25 weeks.

In cohort 1, the median age at first study dose was 166 postnatal days (range 52 to Per intention-to-treat analyses, this participant was included in the $0.125 \mathrm{mg} / \mathrm{kg}$ dosing group.279) and the median first study dose was $0.97 \mathrm{mg} / \mathrm{kg}(0.42-2.09 \mathrm{mg} / \mathrm{kg})$. The median number of study doses per participant in cohort 1 was 26 , with a range from 3 to 29 . During the study period, fifteen $(60 \%)$ participants were treated with enteral dosing every $6 \mathrm{~h}, 8(32 \%)$ were treated with enteral dosing every $8 \mathrm{~h}, 1(4 \%)$ was treated with variable enteral dosing every $6-8 \mathrm{~h}$, and 1 (4\%) participant was treated with IV dosing every $6 \mathrm{~h}$.

In cohort 2, seven infants received a single IV sildenafil dose of $0.25 \mathrm{mg} / \mathrm{kg}$. Two infants were enrolled in a second dosing group $(0.125 \mathrm{mg} / \mathrm{kg})$ following a protocol modification due to a SAE related to hypotension in the first dosing group. One participant in the second dosing group received a dose of $0.25 \mathrm{mg} / \mathrm{kg}$, instead of $0.125 \mathrm{mg} / \mathrm{kg}$. Per intention-to-treat, this participant was included in the $0.125 \mathrm{mg} / \mathrm{kg}$ dosing group for the analyses.

\section{Interim safety analysis}

A planned interim safety analysis and PK analysis was completed after the first 12 participants were enrolled into cohort 1 . The purpose was to determine the appropriate dose for use in cohort 2. Enrollment to cohort 1 continued during this analysis. The Sponsor requested an unplanned cohort 2 safety analysis after seven participants were enrolled and one participant experienced a SAE related to hypotension. This participant received the IV study dose of sildenafil over $45 \mathrm{~min}$, instead of over $90 \mathrm{~min}$ as 
Table 1. Demographics and dosing information in a phase I study of sildenafil in premature infants. Infants in cohort 1 were receiving sildenafil per clinical care prior to enrollment. Infants in cohort received a single IV dose of sildenafil.

\begin{tabular}{|c|c|c|c|}
\hline & \multirow{2}{*}{$\begin{array}{l}\text { Cohort } 1(n=25) \\
\text { Multiple doses }\end{array}$} & \multicolumn{2}{|l|}{ Cohort $2(n=9)$ Single IV Dose } \\
\hline & & Dose group $0.25 \mathrm{mg} / \mathrm{kg}(n=7)$ & Dose group $0.125 \mathrm{mg} / \mathrm{kg}(n=2)$ \\
\hline $\begin{array}{l}\text { Age at enrollment (days) Median } \\
\text { (Min, Max) }\end{array}$ & $166(52,279)$ & $17(7,40)$ & $29(22,36)$ \\
\hline $\begin{array}{l}\text { Gestational age (weeks) Median } \\
\text { (Min, Max) }\end{array}$ & $25(22,28)$ & $25(24,27)$ & $24(23,24)$ \\
\hline Male (\%) & 60 & 71 & 50 \\
\hline Black & 72 & 29 & 50 \\
\hline Not reported/More than 1 race & 8 & 14 & 0 \\
\hline Birth weight (g) Median (Min, Max) & $650(450,1215)$ & $816(570,980)$ & $537(425,649)$ \\
\hline $\begin{array}{l}\text { Weight at enrollment (g) Median } \\
\text { (Min, Max) }\end{array}$ & $4790(1360,8055)$ & $747(670,1242)$ & $760(590,930)$ \\
\hline $\begin{array}{l}\text { Number of study doses Median } \\
\text { (Min, Max) }\end{array}$ & $26(3,29)$ & 1 & 1 \\
\hline \multicolumn{4}{|c|}{$\begin{array}{l}\text { IV intravenous, } g \text { grams, } \mathrm{mg} \text { milligrams, } \mathrm{kg} \text { kilograms. } \\
\text { a First clinical care doses in cohort } 1 \text { were the } 6 \text { previous doses before consent; }{ }^{\mathrm{b}} \text { Study doses in cohort } 1 \text { occurred for } 7 \text { days after consent. } \\
{ }^{\mathrm{b}} \text { Study doses in cohort } 1 \text { occurred for } 7 \text { days after consent. }\end{array}$} \\
\hline
\end{tabular}

indicated in the study protocol. Enrollment to cohort 2 was suspended during this time and additional data was requested on MAP measurements, concomitant medications, laboratory data, and site procedures. The analysis was reviewed by the DMC. The protocol team, the Sponsor, and the DMC modified the protocol to address the decrease in MAP values seen in one participant by reducing the study dose to $0.125 \mathrm{mg} / \mathrm{kg}$ and increasing the flush time to $60 \mathrm{~min}$. The study was resumed and 2 additional participants were enrolled under the new protocol. No new drug-related SAEs were reported.

\section{Safety data}

In cohort 1, there were $13 \mathrm{AEs}$ and 8 infants had at least $1 \mathrm{AE}$ (Table 2). One event, cardiogenic shock, was classified as a SAE and determined not to be related to sildenafil. In cohort 2, there were ten $A E s$ in seven participants (eight $A E s$ in the $0.25 \mathrm{mg} / \mathrm{kg}$ dosing group, and two AEs in the $0.125 \mathrm{mg} / \mathrm{kg}$ group). SAEs in cohort 2 in the first dosing group included hypotension, pneumothorax, and acute respiratory failure. Hypotension was determined to be drug related, and occurred after study dose was infused over $45 \mathrm{~min}$, instead of $90 \mathrm{~min}$. In the second dosing group, which opened following an interim safety analysis, there was $1 \mathrm{SAE}$ (necrotizing enterocolitis) that was determined not to be related to sildenafil.

There were no AEs related to elevated transaminases. In cohort 1 , the median (range) change from baseline to follow-up in the 7 days following first study dose was $-2(-16,209) \mathrm{U} / \mathrm{L}$ for AST and $1.5(-22,146) \mathrm{U} / \mathrm{L}$ for ALT (Table 3$)$. In the $0.25 \mathrm{mg} / \mathrm{kg}$ dosing group of cohort 2, the median change from baseline to follow-up at $24 \mathrm{~h}$ after study dose was $1(-19,55) \mathrm{U} / \mathrm{L}$ for AST and $1(-10$, 86) $\mathrm{U} / \mathrm{L}$ for ALT. Both participants in the $0.125 \mathrm{mg} / \mathrm{kg}$ dosing group had decreases in AST and ALT following study dose.

Low blood pressure and hypotension were the primary safety events of interest for this study. In the $0.25 \mathrm{mg} / \mathrm{kg}$ dosing group, two infants were identified as meeting study criteria for low blood pressure (one MAP $<G A$ ). No participants met criteria for the study definition of hypotension ( 2 MAP measurements $<G A$ ), however one participant experienced a hypotensive event of sufficient clinical significance to be deemed a SAE by the site investigator. The hypotensive event occurred due to a protocol deviation in which the infusion time on the pump was entered in error and did not account for the volume in tubing, resulting in sildenafil infusion given over 45 min instead of over $90 \mathrm{~min}$. There were no reported episodes of low blood pressure or hypotension (based on refined definitions of MAP $<$ PMA) in the $0.125 \mathrm{mg} / \mathrm{kg}$ dosing group. Change from baseline MAP measurements displayed in the Fig. 1 demonstrates that the greatest decrease from baseline MAP occurred at 2 hours after start of drug infusion.

\section{DISCUSSION}

In this phase I study of sildenafil in a small cohort of premature infants, we found that sildenafil was well tolerated by the study population. We evaluated the safety of sildenafil in a small cohort of infants born extremely premature by reviewing AEs, measurements of AST and ALT, and intensive blood pressure monitoring. Out of 23 total AEs, only one, a SAE involving hypotension related to a protocol deviation due to an increase in drug infusion rate, was related to study drug. There were no AEs related to elevated transaminases. Our finding that increased rate of sildenafil infusion may lead to hypotension demonstrates the importance of early phase trials in gathering safety data to determine correct drug infusion time. Importantly, it cannot be concluded from our findings that the current off-label use of sildenafil in preterm infants is safe.

The pathophysiology of BPD includes abnormal alveolar and pulmonary vascular growth due to an arrest in normal lung development and inhibition of vascular endothelial growth factor (VEGF) [14-16]. Sildenafil might be effective in promoting normal 
Table 2. Adverse events in a phase I study of sildenafil in premature infants.

\section{Cohort $1(n=25)$ Multiple doses}

Number of adverse events, $N$

Participants with $\geq 1$ adverse event, $N$ (\%)

Participants with $\geq 1$ serious adverse event, $N(\%)$

Cardiogenic shock

$13^{\mathrm{a}}$

1 (4)

Hypotension

Pneumothorax

Necrotizing enterocolitis

Acute respiratory failure

Participants with drug-related adverse events,

$N(\%)$

Participants with low blood pressure ${ }^{\mathrm{e}}, \mathrm{N}(\%)$

Participants with hypotension ${ }^{f}, N(\%)$
Cohort $2(n=9)$ Single IV dose

\begin{tabular}{|c|c|}
\hline $\begin{array}{l}\text { Dose group } 0.25 \mathrm{mg} / \mathrm{kg} \\
(n=7)\end{array}$ & $\begin{array}{l}\text { Dose group } 0.125 \mathrm{mg} / \mathrm{kg} \\
(n=2)\end{array}$ \\
\hline $8^{b}$ & $2^{c}$ \\
\hline $5(71)$ & $2(100)$ \\
\hline $3(43)$ & $1(50)$ \\
\hline
\end{tabular}

0

$1(14) \quad 0$

$1(14)$

$0 \quad 1(50)$

$1(14) \quad 0$

$1(14)^{\mathrm{d}} \quad 0$

N/A $2(29) \quad 0$

N/A $\quad 0 \quad 0$

IV intravenous, $\mathrm{mg}$ milligrams, $\mathrm{kg}$ kilograms, MAP mean arterial pressure, $P M A$ postmenstrual age (gestational age + postnatal age).

${ }^{a}$ Cardiogenic shock, laryngomalacia, pyrexia, otitis media, tracheitis, tracheobronchitis, hypokalemia, agitation $(n=2)$, polyuria, pneumothorax, rales, respiratory failure.

bBradycardia, decreased hematocrit, decreased free thyroxine, acute respiratory failure, apnea, pneumothorax, respiratory disorder, hypotension.

${ }^{c}$ Necrotizing enterocolitis, decreased oxygen saturation.

dHypotension.

e Low blood pressure was defined as MAP $<$ GA in the $0.25 \mathrm{mg} / \mathrm{kg}$ dosing group, and MAP $<\mathrm{PMA}$ in the $0.125 \mathrm{mg} / \mathrm{kg}$ dosing group.

fHypotension was defined as 2 MAPs $<$ GA in the $0.25 \mathrm{mg} / \mathrm{kg}$ dosing group, and 2 MAPs $<$ PMA in the $0.125 \mathrm{mg} / \mathrm{kg}$ dosing group.

Table 3. Aspartate Transaminase (AST) and Alanine Transaminase (ALT) measurements in a phase I study of sildenafil in premature infants.

\begin{tabular}{|c|c|c|c|}
\hline & \multirow{2}{*}{$\begin{array}{l}\text { Cohort } 1(n=25) \\
\text { Multiple doses }\end{array}$} & \multicolumn{2}{|c|}{ Cohort $2(n=9)$ Single IV dose } \\
\hline & & $\begin{array}{l}\text { Dose group } \\
0.25 \mathrm{mg} / \mathrm{kg} \\
(n=7)\end{array}$ & $\begin{array}{l}\text { Dose group } \\
0.125 \mathrm{mg} / \mathrm{kg} \\
(n=2)\end{array}$ \\
\hline \multicolumn{4}{|c|}{ AST (U/L), Median (Min, Max) } \\
\hline Baseline AST & $36(17,59)$ & $34(14,120)$ & $53.5(49,58)$ \\
\hline Follow-up AST & $35(19,237)$ & $26(13,175)$ & $30(23,37)$ \\
\hline $\begin{array}{l}\text { Change from } \\
\text { baseline to } \\
\text { follow-up AST }\end{array}$ & $-2(-16,209)$ & $1(-19,55)$ & $-23.5(-26,-21)$ \\
\hline \multicolumn{4}{|c|}{ ALT (U/L), Median (Min, Max) } \\
\hline Baseline ALT & $18(7,54)$ & $24(4,108)$ & $12.5(11,14)$ \\
\hline Follow-up ALT & $16.5(8,161)$ & $14(5,156)$ & $9.5(9,10)$ \\
\hline $\begin{array}{l}\text { Change from } \\
\text { baseline to } \\
\text { follow-up ALT }\end{array}$ & $1.5(-22,146)$ & $1(-10,86)$ & $-3(-5,-1)$ \\
\hline
\end{tabular}

AST aspartate transaminase, ALT alanine transaminase, IV intravenous, $m g$ milligrams $\mathrm{kg}$, kilograms, $U / L$ units per liter.

vascular growth and thereby reducing BPD. However, studies of sildenafil in premature infants at risk for or diagnosed with BPD are limited. A randomized controlled trial of 20 preterm infants $<28$ weeks gestational age receiving mechanical ventilation on postnatal day 7 found no improvement in short-term respiratory outcomes in infants receiving 4 weeks of sildenafil $3 \mathrm{mg} / \mathrm{kg} /$ day compared to placebo [17]. A retrospective study of 25 preterm infants with a median gestational age of 28 weeks with chronic lung disease ( $72 \%$ with BPD) and pulmonary hypertension demonstrated that sildenafil of $1.5-8 \mathrm{mg} / \mathrm{kg} /$ day resulted in 22 patients with hemodynamic improvement determined by echocardiogram [18].
Our use of single-dose sildenafil in cohort 2 aligns with FDA guidance that single-dose studies, while offering no direct therapeutic benefit to the infant, are permissible if the risk of exposure represents a minor increase over minimal risk and is likely to yield generalizable knowledge about the participants' medical condition [19]. Parents who consent to enrollment in early phase trials for potential therapeutics are often motivated by a desire to help future infants [20]. The risks of enrollment in our study were mitigated by the inclusion of infants receiving sildenafil per clinical care in cohort 1 and the use of low doses of sildenafil in cohort 2 to establish PK and safety prior to proceeding with multiple dose-escalating regimens in the phase II trial of sildenafil. We speculate that the lack of direct benefit to the infant, which is common in single-dose phase I trials, may explain the slow pace of enrollment in this study.

There are several notable strengths of this study, including the opportunistic nature of the study design, which permitted inclusion of infants receiving sildenafil per clinical care. An opportunistic study allows investigators to collect PK and safety data, after obtaining informed consent, from participants already receiving drugs of interest. PK samples are obtained with routine laboratory draws or using scavenged samples, minimizing study-associated blood sampling. This strategy generates meaningful PK and safety data for drugs where dosing has not been established [21]. Our group successfully used opportunistic approaches to collect data on fluconazole, clindamycin, metronidazole, and piperacillintazobactam to design phase II and III trials and submit data to the FDA to inform pediatric labeling [22-25].

Our study also addresses the importance of conducting early phase trials prior to randomized controlled trials to characterize drug safety, efficacy, and optimal dose. Knowledge gained from early phase trials are particularly important for BPD given that the majority of randomized controlled trials of drugs for the prevention or treatment of BPD have not demonstrated efficacy and no drugs are currently FDA-labeled for BPD prevention or treatment [26]. This study was performed under an IND application and complies with FDA guidance that PK studies be conducted to 
a)

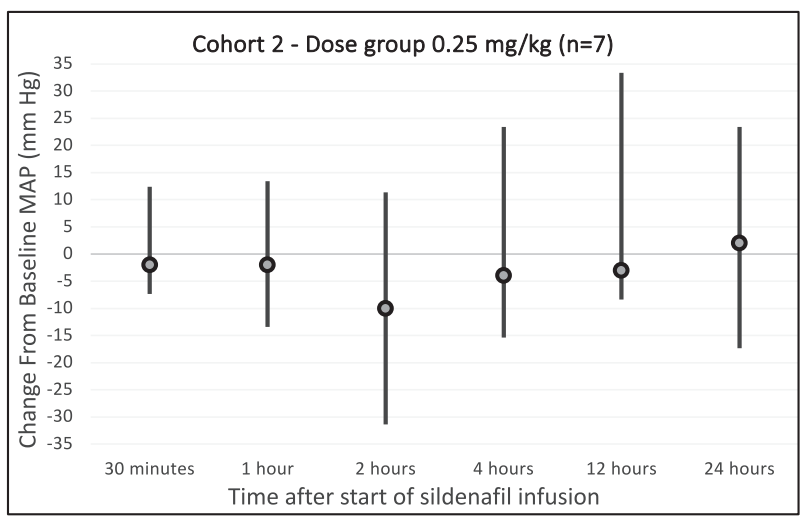

b)

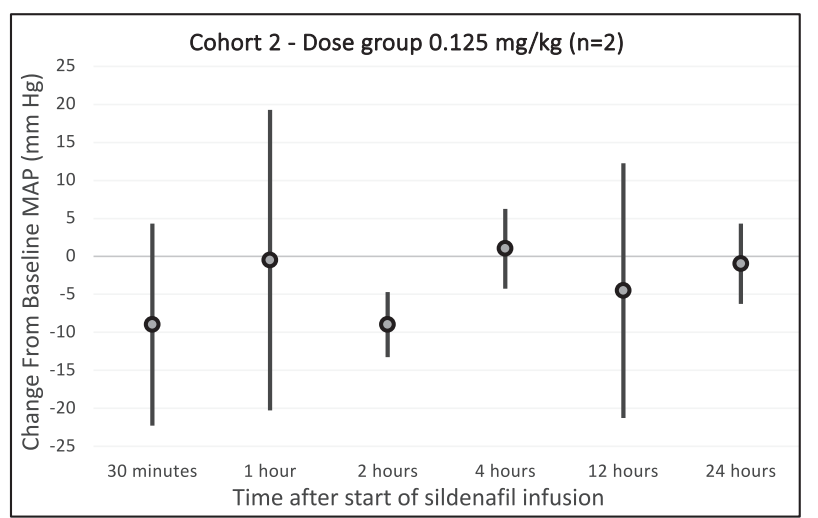

Fig. 1 Change from baseline Mean Arterial Pressure (MAP) over time following start of IV sildenafil infusion. a The dose group $0.25 \mathrm{mg} / \mathrm{kg}$ and $\mathbf{b}$ dose group $0.125 \mathrm{mg} / \mathrm{kg}$ in a phase I study of sildenafil in premature infants. Circles represent median change and whiskers represent minimum and maximum value.

establish the correct dose prior to evaluating efficacy in a pediatric population [27].

Our study was limited by the small number of patients in cohort 2, with the study ending early due to slow enrollment, and changes made to the single IV dose protocol after the interim safety analysis. The infants in cohort 1 were older than those in cohort 2, and as a result, the safety profiles may differ between these groups. We did not collect physiological parameters of BPD or $\mathrm{PH}$ which could be used to correlate exposure with preliminary drug efficacy. Furthermore, the PK simulation results are limited by the lack of a widely accepted exposure target for sildenafil in the setting of BPD. While the PK results from this study determined that co-administration of fluconazole reduced sildenafil clearance [13], our ability to relate reduced drug clearance with safety is limited by the small number of participants receiving fluconazole $(n=4)$. However, a retrospective analysis of electronic health records data from this group did not identify a clear relationship between simulated sildenafil exposure and hypotension [28]. Despite these limitations, this study provides an important first step in evaluating sildenafil as a potential therapy for premature infants with or developing BPD and PH. The safety data related to drug infusion time characterized by this study informed the dosing for the follow-up phase II trial of sildenafil in premature infants at risk for BPD. The first cohort in the dose-escalating phase II trial will receive an IV dose of $0.125 \mathrm{mg} / \mathrm{kg}$ every $8 \mathrm{~h}$, with subsequent cohorts receiving higher doses following interim safety analyses.

\section{REFERENCES}

1. Mourani PM, Sontag MK, Younoszai A, Miller Jl, Kinsella JP, Baker CD, et al. Early pulmonary vascular disease in preterm infants at risk for bronchopulmonary dysplasia. Am J Respir Crit Care Med. 2015;191:87-95.

2. Collaco JM, Dadlani GH, Nies MK, Leshko J, Everett AD, McGrath-Morrow SA. Risk factors and clinical outcomes in preterm infants with pulmonary hypertension. PLoS One. 2016;11:e0163904.

3. An HS, Bae EJ, Kim GB, Kwon BS, Beak JS, Kim EK, et al. Pulmonary hypertension in preterm infants with bronchopulmonary dysplasia. Korean Circ J. 2010;40:131-6.

4. Khemani E, McElhinney DB, Rhein L, Andrade O, Lacro RV, Thomas KC, et al. Pulmonary artery hypertension in formerly premature infants with bronchopulmonary dysplasia: clinical features and outcomes in the surfactant era. Pediatrics. 2007;120:1260-9.

5. Slaughter JL, Pakrashi T, Jones DE, South AP, Shah TA. Echocardiographic detection of pulmonary hypertension in extremely low birth weight infants with bronchopulmonary dysplasia requiring prolonged positive pressure ventilation. J Perinatol. 2011;31:635-40.

6. Jackson W, Hornik CP, Messina JA, Guglielmo K, Watwe A, Delancy G, et al In-hospital outcomes of premature infants with severe bronchopulmonary dysplasia. J Perinatol. 2017;37:853-6.

7. Kim DH, Kim HS, Choi CW, Kim EK, Kim BI, Choi JH. Risk factors for pulmonary artery hypertension in preterm infants with moderate or severe bronchopulmonary dysplasia. Neonatology. 2012;101:40-6.

8. Bhat R, Salas AA, Foster C, Carlo WA, Ambalavanan N. Prospective analysis of pulmonary hypertension in extremely low birth weight infants. Pediatrics. 2012;129:e682-9.

9. Bruno CJ, Meerkov M, Capone C, Vega M, Sutton N, Kim M, et al. CRIB scores as a tool for assessing risk for the development of pulmonary hypertension in extremely preterm infants with bronchopulmonary dysplasia. Am J Perinatol. 2015;32:1031-7.

10. Shankaran S, Laptook AR, Pappas A, McDonald SA, Das A, Tyson JE, et al. Effect of depth and duration of cooling on death or disability at age 18 months among neonates with hypoxic-ischemic encephalopathy: a randomized clinical trial. JAMA. 2017;318:57-67.

11. Ahsman MJ, Witjes BC, Wildschut ED, Sluiter I, Vulto AG, Tibboel D, et al. Sildenafil exposure in neonates with pulmonary hypertension after administration via a nasogastric tube. Arch Dis Child Fetal Neonatal Ed. 2010;95:F109-14.

12. Thompson EJ, Perez K, Hornik CP, Smith PB, Clark RH, Laughon M. Sildenafil exposure in the neonatal intensive care unit.Am J Perinatol. 2019;36:262-7.

13. Gonzalez D, Laughon MM, Smith PB, Ge S, Ambalavanan N, Atz A, et al. Population pharmacokinetics of sildenafil in extremely premature infants. $\mathrm{Br} J$ Clin Pharmacol. 2019:85:2824-37.

14. Fujioka K, Shibata A, Yokota T, Koda T, Nagasaka M, Yagi M, et al. Association of a vascular endothelial growth factor polymorphism with the development of bronchopulmonary dysplasia in Japanese premature newborns. Sci Rep. 2014; 4:4459.

15. Yun EJ, Lorizio W, Seedorf G, Abman SH, Vu TH. VEGF and endothelium-derived retinoic acid regulate lung vascular and alveolar development. Am J Physiol Lung Cell Mol Physiol. 2016;310:L287-98.

16. Jobe AH. The new bronchopulmonary dysplasia. Curr Opin Pediatr. 2011;23: 167-72.

17. Konig K, Barfield CP, Guy KJ, Drew SM, Andersen CC. The effect of sildenafil on evolving bronchopulmonary dysplasia in extremely preterm infants: a randomised controlled pilot study. J Matern Fetal Neonatal Med. 2014;27:439-44.

18. Mourani PM, Sontag MK, Ivy DD, Abman SH. Effects of long-term sildenafil treatment for pulmonary hypertension in infants with chronic lung disease. J Pediatr. 2009;154:379-84. 84.e1-2.

19. 21 CFR Sec. 50.53 Clinical investigations involving greater than minimal risk and no prospect of direct benefit to individual subjects, but likely to yield generalizable knowledge about the subjects' disorder or condition. 2015.

20. Tromp K, Zwaan CM, van de Vathorst S. Motivations of children and their parents to participate in drug research: a systematic review. Eur J Pediatr. 2016;175:599-612.

21. Laughon MM, Benjamin DK Jr., Capparelli EV, Kearns GL, Berezny K, Paul IM, et al. Innovative clinical trial design for pediatric therapeutics. Expert Rev Clin Pharm. 2011;4:643-52.

22. Watt KM, Benjamin DK Jr., Cheifetz IM, Moorthy G, Wade KC, Smith PB, et al. Pharmacokinetics and safety of fluconazole in young infants supported with extracorporeal membrane oxygenation. Pediatr Infect Dis J. 2012;31:1042-7. 
36

23. Gonzalez D, Delmore P, Bloom BT, Cotten CM, Poindexter BB, McGowan E, et al. Clindamycin pharmacokinetics and safety in preterm and term infants. Antimicrob Agents Chemother. 2016;60:2888-94.

24. Cohen-Wolkowiez M, Sampson M, Bloom BT, Arrieta A, Wynn JL, Martz K, et al. Determining population and developmental pharmacokinetics of metronidazole using plasma and dried blood spot samples from premature infants. Pediatr Infect Dis J. 2013;32:956-61.

25. Cohen-Wolkowiez M, Benjamin DK Jr., Ross A, James LP, Sullivan JE, Walsh MC, et al. Population pharmacokinetics of piperacillin using scavenged samples from preterm infants. Ther Drug Monit. 2012;34:312-9.

26. Beam KS, Aliaga S, Ahlfeld SK, Cohen-Wolkowiez M, Smith PB, Laughon MM. A systematic review of randomized controlled trials for the prevention of bronchopulmonary dysplasia in infants. J Perinatol. 2014;34:705-10.

27. US Food and Drug Administration. General Clinical Pharmacology Considerations. Guidance for Industry. 2014. https://www.fda.gov/downloads/Drugs/ GuidanceComplianceRegulatorylnformation/Guidances/UCM425885.pdf.

28. Hornik CP, Onufrak NJ, Smith PB, Cohen-Wolkowiez M, Laughon MM, Clark RH, et al. Association between oral sildenafil dosing, predicted exposure, and systemic hypotension in hospitalised infants. Cardiol Young. 2018;28:85-92.

\section{ACKNOWLEDGEMENTS}

Best Pharmaceuticals for Children Act-Pediatric Trials Network Steering Committee: Danny Benjamin, Edmund Capparelli, Erin Campbell, Greg Kearns, lan Paul, Julie Autmizguine, Kanecia Zimmerman, Kelly Wade, Perdita Taylor-Zapata, Peter Hoffmann, Ravander Anand, Tom Green.

\section{AUTHOR CONTRIBUTIONS}

DG, PBS, NA, AMA, GMS, DS, GM, BBP, SKA, MM, MCW, CPH, MML: Designed the study and enrolled infants in the trial. KM: Performed the analysis. WJ: Wrote the first draft of the manuscript. DG, PBS, NA, AMA, GMS, CDH, DS, GM, BBP, SKA, MM, MCW, KM, $\mathrm{CPH}$, and MML: Reviewed and made significant edits to the manuscript.

\section{FUNDING}

Eunice Kennedy Shriver National Institute of Child Health and Human Development, Grant/Award Number: HHSN275201000003I.

\section{COMPETING INTERESTS}

The authors declare no competing interests.

\section{ADDITIONAL INFORMATION}

Correspondence and requests for materials should be addressed to Wesley Jackson.

Reprints and permission information is available at http://www.nature.com/ reprints

Publisher's note Springer Nature remains neutral with regard to jurisdictional claims in published maps and institutional affiliations. 